\title{
The Mental Capacity Act: 10 years on - the key learning areas for health care professionals
}

This article was published in the following Dove Press journal:

Nursing: Research and Reviews

\section{Helen Marshall' \\ Sally Sprung ${ }^{2}$}

'Mersey Care NHS Foundation Trust, Liverpool, UK; ${ }^{2}$ School of Nursing and Allied Health, Liverpool John Moores University, Liverpool, UK
Correspondence: Helen Marshall Mersey Care NHS Trust, Burlington House, 2nd floor, south entrance, Crosby Road North, Waterloo, Liverpool L22 OQB, UK

Email helen_m_82@hotmail.com

\begin{abstract}
The Mental Capacity Act (MCA) became statute law in England and Wales from October 2007 and was described as a visionary piece of legislation for its time, which had the potential to give people a voice and an opportunity to be heard. However, 10 years on, the Act is not being utilized in the UK as was intended. A scrutiny report published by the House of Lords in $2014^{1}$ identified that the MCA was not embedded into the everyday practice of health care professionals due to the lack of knowledge, understanding, and confidence in the application of the basic principles of the MCA in clinical settings. The Department of Health produced a response document, which placed improvements in the implementation of the MCA at the forefront of the political agenda in order to empower and safeguard those deemed the most vulnerable in society. It is envisaged that this response will require a shift in the culture of health care professionals to view the MCA as a mandatory part of clinical practice and not an option. With the prevalence of people with impairment of mind or brain set to rise in the coming years, it is of vital importance that the MCA is used proactively in order to provide a protection for both patients and practitioners.
\end{abstract}

Keywords: mental capacity, nurse, experience, NHS, knowledge, confidence, advanced planning, global, MCA

\section{Introduction}

The Mental Capacity Act (MCA) 2005 is applicable in the UK to all people aged 16 years and older. The MCA is a piece of empowering legislation, which has the potential to give people a voice. ${ }^{1}$ In the past, if a person lacked the mental capacity to understand the information provided by health care professionals to make a decision, decisions were often made about them, rather than with them. As a result, a gap was identified in relation to the legal detention of a person in a hospital or care home, and the Deprivation of Liberty Safeguards was added and became law on April 1, 2009.

Prior to the introduction of the MCA, the assessment of mental capacity by health care professionals was paternalistic, risk averse, subjective, and not wholly incorporating what the person's wishes may be. Therefore, the implementation of a robust framework, which professionals must follow, when decisions are to be made, that could reduce practitioner bias was welcomed.

The MCA allows and empowers people to make decisions and plan for the future, should the time come when decision-making abilities are compromised. ${ }^{2}$ Forward planning may include creating an Advance Decision to Refuse Treatment (ADRT), which allows a person to document the specific medical treatment they wish to receive, even if this directive puts life at risk. The MCA also permits an individual to nominate 
a Lasting Power of Attorney (LPA) regarding health and welfare and/or property and finance, which when registered with the Office of the Public Guardian becomes legally binding. In contrast, if there is an absence of advance planning, a health care professional may be responsible for making a decision on behalf of another and this is known as "acting in best interests".

In western countries including the UK, advance care planning is established to promote communication between health care professionals and patients to plan for future care, thus ensuring that their personal wishes are respected, should the patient choose to have these wishes documented. In USA, for example, advance planning was first introduced to the legal structure approximately 35 years ago with the living will and a health care proxy. However, in developing countries, advance planning is not widely accepted and it could be suggested that this is due to a difference in cultural beliefs and-level of health literacy. ${ }^{3}$ A case study from a hospital in Australia revealed the significance of cultural beliefs when making a choice to refuse treatment. It also highlights the complexity and level of responsibility involved for health care professionals assessing mental capacity when the decision relates to life saving treatment. ${ }^{4}$ This study related to a Sicilian woman refusing surgery, which would result in a scar to her neck, which in her native country was considered to be dishonorable and associated with the Mafia. Therefore, she refused surgery, a decision which potentially could be fatal. All health care professionals involved deemed this lady competent to make the decision and, although her approach to life and death was unconventional, did not consider her to have a cognitive impairment, which may influence her decision. However, due to the severity of risk associated with her decision, a neuropsychological assessment took place, which confirmed a cognitive impairment, meaning that she was unable to rationally weigh up risks and benefits. Consequently, the decision was made by her sons and they chose for her to have the surgery. Postsurgery, the patient was happy with the outcome and made a full recovery. ${ }^{4} \mathrm{Had}$ her original decision been respected she may have died. Nevertheless, a specialist opinion was sought due to the level of risk associated with the refusal of treatment. Initially, all health care professionals agreed that this patient had the capacity to refuse surgery, thus suggesting the magnitude of the conflicts and difficulties that exist in multifaceted cases. It also indicates the decision-making differences when comparing a generalist assessment with a specialist assessment.

The number of those diagnosed with an impairment of the mind or brain is reported to be 930,400 adults living with a learning disability in England ${ }^{5}$ and a further 850,000 people living with Dementia in the UK. ${ }^{6}$ Furthermore, there are approximately 340,934 admissions to hospital per year in the UK due to an acquired brain injury. ${ }^{7}$ As the prevalence of dementia increases, it is significant that health care professionals, including nurses, understand the MCA legislation and how this should be applied in clinical practice. Therefore, this article explores the main findings from the literature, which impact upon a health care professional's ability to understand the legislation.

\section{Recent scrutiny}

The MCA was designed as an empowering piece of legislation, which had the potential to change the lives of many. However, results from the House of Lords postlegislative scrutiny report identified that the MCA is not working as parliament intended. ${ }^{1}$ Although the MCA is held in high regard, the empowering philosophy of the Act is not being delivered, as it is not fully embedded into the everyday practice of health care professionals. The House of Lords concluded that a barrier to the successful implementation of the MCA is due to a lack of central ownership and responsibility, thus resulting in the MCA being largely unimplemented. To respond to the House of Lords report, the Government produced "Valuing every voice, respecting every right: making the case for the Mental Capacity Act" 8 to outline how they would address the concerns raised in the scrutiny report. The Department of Health considers that introduction of a Mental Capacity Advisory Board will provide robust monitoring of implementation of the MCA to ensure that it is applied in all National Health Service (NHS) organizations and that clinical areas are delivering with commitment and responsibility. The Office of the Public Guardian, the regulators of appointees of LPA, is also committed to increase the level of awareness of health care practitioners on the key principles of the MCA. They are planning to implement work streams in order to embed the MCA into practice. It is thought that raising an increased cognizance of the MCA will create a positive culture shift and the MCA will be used as intended, as an empowering tool. This will support decision making and protect vulnerable people from paternalism and risk averse decision making.

\section{Methods}

A search on the literature was undertaken using set time parameters, November 2012 to November 2017. The time frame was restricted to the last 5 years of publication in order to capture the most recent evidence base. A thorough search of Government papers and electronic databases were made, 
which included Discover, MEDLINE, ScienceDirect, Ovid, and CINAHL. The keywords used were mental capacity, nurse, experience, NHS, knowledge, and confidence. Reference lists obtained from primary papers were scrutinized in order to generate further pieces of work, which met the criteria. A total of 34 sources were critically explored. The main themes derived from the search are as follows:

- The assessment process regarding MCA,

- Understanding of the MCA,

- Section 44 of the MCA,

- Advance planning,

- Best interests.

\section{Assessment}

The first guiding principle of the MCA indicates that we presume that mental capacity is present unless a documented assessment demonstrates otherwise. ${ }^{2}$ Therefore, it is imperative that all health care professionals including nurses are able to confidently perform an assessment of mental capacity in order to enable a valid consent process. However, current evidence suggests that the required knowledge and confidence of nurses to perform an accurate assessment of mental capacity require improvement. ${ }^{1,9}$ Interestingly, data from similar findings in the USA suggest that the competence and quality of capacity assessments among physicians were suboptimal. ${ }^{3}$

The MCA legislation sets a specific framework for professionals to follow when completing the assessment of mental capacity. ${ }^{2}$ Prior to 2005 , mental capacity assessments were resource focused and biased ${ }^{10,11}$ and a pre-existing diagnosed impairment of the mind or brain was the diagnostic threshold that triggered the assessment of mental capacity. However, the literature suggests that mental capacity assessments were unlawfully carried out when there were no diagnosed impairment of the mind or brain and no reason to doubt capacity and occurred when people labeled as "a difficult patient" were perceived by others as making unwise decisions with an element of risk attached. ${ }^{1,11,12}$ Whereas under the new legislation, if a person does meet the diagnostic threshold of the MCA, the health care professional will initiate the functional element of the assessment, which requires a person to be able to understand the decision, which is to be made, weighs up the risks and benefits, retains this information, and communicates a decision. If a person is unable to do one or more of these tasks, they would be considered to be lacking the mental capacity to make the decision for which they have been assessed. ${ }^{2}$ All health care professionals should feel able and competent to assess capacity in relation to a specific decision. However, in a study by Williams et al, ${ }^{13}$ it was found that participants would often defer the assessment of capacity to others who they thought were more expert in the field, such as a psychiatrist, when in actual fact, a psychiatrist was unlikely to be the most appropriate assessor in routine, noncomplex, or specialist cases. It was also found that the reason for deferring assessment was a reluctance to accept the responsibility to determine that a patient lacked the capacity to make a decision.

It is appreciated that completing a mental capacity assessment in difficult cases can be complex. Personal views can influence a judgment to suggest a person lacks capacity into making a decision rather than empowering them to make their own decision, either due to the lack of knowledge from the health care professional or the perceived associated risk of the choice made. ${ }^{14}$ However, as Lennard ${ }^{15}$ notes, the mandate of the MCA is to protect a person's autonomy and avoid health care professional control. Likewise, if a person makes an unwise decision, which potentially carries an element of risk to safety, assessment of capacity is of vital importance. There have been occasions when the assessor may not agree with a personal decision, interpreted that decision as a person being unable to understand the consequences or potential risks involved, and has therefore suggested that the person lacks the mental capacity to make such a decision, which may not be the case. ${ }^{16}$ However, in all circumstances, the MCA allows decisions made by professionals to be challenged via a legal framework, thus empowering people with a diagnosed impairment of the mind or brain. Equally, the MCA can provide a protective shield for health care professionals from litigation should decisions ever be called into question. ${ }^{13}$ Conversely, it is appreciated that the assessment of mental capacity with a person whose lucidity and understanding can be changeable can be a difficult task in itself. ${ }^{17}$ Furthermore, impulsive behavior may be misconstrued as a lack of understanding, which also may not be the case. These findings are supported by Emmett et $\mathrm{al}^{16}$ who found that mental capacity assessments could be outcome driven, rather than based on a person supported to make a personal decision. Moreover, due to the close relationship formed between health care staff and patients, an element of risk antipathy is possible as nurses are accountable for the patient's welfare and maintaining patient safety. ${ }^{16}$ It must be appreciated, however, that people with a recognized impairment of the mind or brain have the same rights to make risky choices, as those who do not have impairment. Ultimately, the concept of shared decision making will only be successful if health care professionals acknowledge and accept that while patients often make decisions thought to be the "right" ones, they also have the right to make decisions that 
health care professionals may view as the "wrong" ones. ${ }^{18,19}$ Nevertheless, as Lennard ${ }^{15}$ notes, it can be a stressful time for health care professionals when patients make unwise choices that carry a potential risk of significant harm to well-being.

\section{Understanding of the MCA}

A House of Lords postlegislative scrutiny report concluded that the MCA and its principles are not always directly embedded into the practice of health care professionals, suggesting that a lack of awareness and understanding in relation to the MCA exists. The literature supports this assertion with similar outcomes and findings. ${ }^{9,20-24}$ However, for health care professionals, there is a professional responsibility to be accountable for personal learning and, therefore, if a gap in knowledge is identified, health care professionals have a duty to be proactive in increasing a knowledge and skills deficit. ${ }^{8}$

Phair and Manthorpe ${ }^{23}$ completed a review in one acute hospital Trust in England regarding the use of the MCA among patients. They found that the overall impression of staff regarding the MCA was negative. Staff viewed the MCA to be an addition to bureaucracy, a litigation risk, and an additional task to complete in a busy clinical environment. However, when the empowering and supportive aspects of the MCA for both patients and staff were discussed, participants looked at the MCA with a different viewpoint and appreciated its potential benefits. Concurrently, Rowley et al ${ }^{24}$ also surveyed 249 health care professionals in an acute hospital in a different part of England, in relation to knowledge of the MCA and found that, overall, there was a low standard of MCA knowledge and, as such, concluded that this would compromise the health care professionals' ability to meet a legal responsibility to follow the MCA. Therefore, as a result of this work, measures to improve MCA awareness within the Trust were put in place. ${ }^{24}$ These findings provide added validity as both studies were large scale and conducted in different parts of the country yet yielded similar results. ${ }^{23,24}$

In 2012, Manthorpe et $\mathrm{al}^{22}$ conducted a qualitative study consisting of 17 interviews with a purposive sample of volunteer carer agencies, such as Dementia Support, who give MCA advice to patients and families. Largely, participants agreed that the MCA was beneficial to safeguard and enhance the rights of people with dementia, for example, in order to give them a voice, thus ensuring that diagnosis alone is not a presumption of incapacity. ${ }^{22}$ As a result, Manthorpe and Samsi ${ }^{25}$ concluded that the MCA has the potential to empower patients and service users in order to give them greater control over personal decisions.
It is thought that training would enhance both knowledge and confidence in the use of the MCA. However, when Phair and Manthorpe ${ }^{23}$ surveyed 42 staff, all but one advised that they had undertaken MCA training. Yet knowledge and confidence when using the MCA were identified as the areas for improvement. This echoes the findings of Marshall and Sprung ${ }^{21}$ and Willner et $\mathrm{al}^{26}$ who also found that the delivery of MCA training to staff was not a precursor to increased levels of knowledge and confidence. It is suggested that the quality of training could be a contributing factor when assessing potential barriers to the MCA being fully embedded into the practice of health care professionals. Phair and Manthorpe ${ }^{23}$ found that although participants had received training, it was over 2 years prior to participating in the study and the training they received had lasted around 45 minutes and was "tagged on" to a training session focused on consent. It is thought that this approach toward delivering training is not sufficient to give staff the insight into a complex piece of legislation, which is required by statutory law to be embedded into daily clinical practice. ${ }^{23}$ This is supported by the findings of the House of Lords report, which identified that for health care professionals, the MCA appears to be viewed as an optional extra, rather than being central to every aspect of professional practice. ${ }^{1}$ Furthermore, Phair and Manthorpe ${ }^{23}$ also found that MCA policies and procedures lacked detail and were long and complex and not user friendly and, on occasions, some sections were found to still be in "draft" form. In addition, the principles of the MCA were not mentioned in other relevant policies such as "Consent to Examination or Treatment", "Safeguarding Vulnerable Adults", and "Do Not Resuscitate Decisions", thus demonstrating to staff that the ethos of the MCA is not sincerely embedded into the culture of the hospital and, therefore, was seen as a standalone topic. $^{23}$

Willner et $\mathrm{al}^{26}$ also conducted a study within an acute NHS hospital with similar findings to Phair and Manthorpe. ${ }^{23}$ They also found that after attending training, significant gaps in participants' awareness of key MCA issues were still noted. In this study, Willner et $\mathrm{al}^{26}$ provided training to 86 participants from a health and social care background to assess if training had made a positive impact on knowledge, confidence, and ability to apply the MCA principles in clinical practice. It was identified in pretraining interviews that there was no difference in the knowledge of participants who had received MCA training vs those who had not received training. Therefore, this raises the question of how well a training session alone will support the retention of information to be applied successfully in clinical practice. Prior experience of 
using the MCA and an increased exposure in this field of professionals who would potentially use the MCA, such as Learning Disability Services, were cited as positive factors toward increasing the knowledge. This was demonstrated by those professionals achieving higher test scores than those who worked in general medical areas of the hospital. It is proposed that conventional lecture style training may not be the most appropriate way of facilitating people to have a deeper understanding of the MCA legislation. It has been suggested that training should incorporate a case study approach so participants can apply theory to practice using a tangible scenario as opposed to a wholly theoretical viewpoint. ${ }^{26}$ It is important to note that training is considered to be an integral aspect when increasing the knowledge and confidence in a subject area. However, the quality and delivery of training should also be considered when assessing its value in health care and the feasibility of practitioners transferring this knowledge into clinical practice.

A poor working knowledge of the MCA will lead to the poor implementation of the MCA and its principles in the health sector. This not only creates a risk to patient care and experience but also negatively affects staff. The MCA provides protection to health care professionals when working within the principles of the MCA should harm occur to a patient and if decisions are ever called into question. ${ }^{26}$ However, this safeguard will only occur if mental capacity has been assessed correctly and decisions made in accordance with the legislation. Therefore, in order for this to happen, health care professionals must ensure that they are fully informed when working under the remit of the MCA.

\section{Section 44 of the MCA}

New criminal offenses were created with the implementation of the MCA, specifically section $44 .^{2}$ These offenses relate to the ill treatment and willful neglect of those who lack capacity, by a person who is in a relationship of care with the patient. These offenses were created as existing laws did not adequately safeguard the rights of those deemed to be vulnerable and unable to provide a witness statement due to their cognitive impairment, for example, obtaining witness statements from victims with illnesses such as Dementia. ${ }^{20}$ However, unfortunately, there have been fewer prosecutions completed under section 44 of the MCA than originally envisaged, which raises the question of how successful it is to take allegations forward when there is limited victim recall. Manthorpe and Samsi ${ }^{20}$ interviewed 279 dementia practitioners over a 3-year period regarding their understanding of the MCA and knowledge of the new offenses. Participants were interviewed twice over this period. In the main, during the first interview, practitioner's knowledge of the MCA was limited. More positively, at interview 2, within specialist nursing services, there was a vast increase in the awareness of section 44 of the Act. However, the knowledge of care home staff remained limited. Within the care home sector, it is noted that a lack of sustained training and high staff turnover is a potential factor contributing to a lack of knowledge of the MCA in general and this includes section $44{ }^{20,27}$ It is proposed that vulnerable people are being denied access to the judicial system due to a lack of knowledge of health care professionals and a responsiveness to alert authorities. Furthermore, professionals who work in dementia advisory services that are in a position to offer advice and information to the public regarding advance planning did not know about the new offenses of ill treatment and willful neglect. This finding is concerning as it suggests that if those working within this specialist field are unaware of the offenses, then it is unreasonable to expect that a general health care professional will be aware that these offenses exist. This point is further supported by Manthorpe and $\mathrm{Samsi}^{20}$ who also found that there was a lack of knowledge regarding these offenses among participants who came from a dementia support service background. Since this time, the House of Lords ${ }^{1}$ made a recommendation that this part of the MCA should be reviewed in order to provide assurance it meets the test of legal certainty, thus promoting successful prosecutions.

Within the new offenses, it was highlighted by Manthorpe and $\mathrm{Samsi}^{20}$ that there was a potential issue when defining what is meant by the term "willful". For example, neglect can occur as a result of organizational systems and barriers, which impact on the care a person receives rather than individuals being directly at fault. With regard to family care, it is suggested that neglect may be a result of poor knowledge or carer stress and not necessarily willful. It is suggested therefore that this gray area may be a potential factor, which is affecting the rates of prosecutions when applying the legal definition of willful neglect to cases.

\section{Advance planning}

A key empowering element of the MCA is the ability for an individual to make their wishes known in advance, should a time come when they are incapacitated and unable to make a decision themselves at the time a decision is to be made. These wishes become plans that come in the form of a created ADRT document or by appointing an entrusted LPA. It is important that health care professionals understand the advance planning aspect of the MCA in order to confidently 
incorporate these into a plan of care. However, in order to include the wishes of a patient during the assessment, it is essential that professionals such as nurses have the knowledge relating to these aspects of the MCA. If a health care professional knows that an advance decision exists, these wishes must be followed as directed. However, in an emergency situation if an advance decision is not known about and treatment is given, the MCA will protect practitioners against litigation. Yet, once the decision is known, if it is not respected, in contrast, this may amount to a charge of battery. ${ }^{28}$

An ADRT allows a competent individual to refuse a specific medical treatment they would not want to receive should a time come when they are unable to take part in the decision making process. ${ }^{2} \mathrm{~A}$ written refusal can include potentially life-sustaining treatment if it is explicitly written that the decision "is to apply to that treatment even if life is at risk". ${ }^{2}$ An ADRT can conflict with health care professionals' duty of care and wanting to keep patient's safe ${ }^{11}$ while respecting a person's autonomy. An example of this is in the case of "Kings College Hospital NHS Foundation Trust v C"29 where a judge upheld a patient's right to refuse life-sustaining dialysis treatment after a failed suicide attempt at the age of 49 years. The fact that the patient had lost the will to live because life had lost its "sparkle" was not grounds to justify that this was an incapacitated decision.

A study by Bartlett et $\mathrm{al}^{30}$ surveyed 549 adult service users with a self-reported diagnosis of bipolar disorder and 650 psychiatrists in order to gain their views and understanding of advance planning under the MCA. A key finding of this study found that advance planning was rarely used, despite service users identifying it was important and being enthusiastic about the concept. Service users cited a lack of knowledge about how to create an advance decision and felt that it was a complex application process. One service user commented that they had faith that the medical professionals will make the right decisions on their behalf. Participants also described the LPA application process as complex and costly. ${ }^{22}$ In a study by Bartlett et al, ${ }^{30}$ service users were skeptical about making an advance plan, as they felt that the proposed plan would be over ridden if they were sectioned under the Mental Health Act. Psychiatrist feedback concurs with the results from the service users, as they also report encountering a low number of patients in practice who had made any formal advance plans. It is suggested that it would be the role of the psychiatrist to guide patients in relation to this aspect of the MCA. However, it was noted that this may raise a conflict of interest for psychiatrists to advise people with a mental health disorder regarding refusing treatment if they are in a position to provide this treatment, as this conflicts with their professional beliefs. However, in some cases, when a mental health disorder is present it raises the question of did the person have the capacity to make the choice when the advance decision was recorded. In complex cases such as "A local Authority v E May", legal input may be required and a case such as this should be referred to the Court of Protection, whereby a Judge would make an official ruling. ${ }^{31}$

Another aspect of advance planning is the appointment of an LPA. An LPA can be created by an individual aged 18 years and older. An LPA bestows one or more donors the legal right to make decisions regarding health and welfare and/or property and finance on their behalf, should a time come when they are unable to make the decision for themselves. During a holistic assessment, health care professionals must view these legal documents that grant such powers and ensure that they have been authorized by the Office of the Public Guardian and record this information within the patient's documentation in line with record keeping policy, as communication for colleagues. ${ }^{32}$ The health care professional must respect the donor's views and wishes as if they were the patient's own. However, it must be noted that any donor must make decisions for the good of the person and not for their own personal intentions. If it is suspected a donor is abusing their power of trust, this would constitute a safeguarding referral to the local authority. It is important to note that if the patient has never possessed mental capacity to make decisions, such as a severe learning disability since birth, an application can be made to the Court of Protection to become a Deputy of the Court, which has similar powers to an LPA in the UK.

It is appreciated that acting as an LPA and making decisions on another person's behalf, no matter how well you know them, can be difficult and stressful. ${ }^{33}$ Decisions can be particularly difficult if pertaining to the end of life care. Dening et $\mathrm{al}^{33}$ conducted a qualitative study of six people with dementia and family carers. It was found that the end of life preferences made by the individual with dementia was not always consistent with what the carers believed the person would want. Thus, appearing to demonstrate even close relatives cannot confidently predict the wishes of another person. Consequently, this poses the question of how confident a health care professional can be to advocate for another person reliably. However, if possible, it is imperative for health care professionals to gather life stories and experiences from patients, this will provide a valuable insight in making decisions in order to inform the aspect of any past and present wishes, which may need to be considered. ${ }^{18}$ 
If there have been no advance plans created, health care professionals such as nurses may be considered as the decision maker if a person is unable to make a decision at the time it needs to be made, while keeping the patient at the center of the process. Therefore, it is vitally important that health care professionals understand the MCA and how to use the legislation in clinical practice.

\section{Best interests}

The fourth guiding principle of the MCA states that "an act done, or decision made, under this Act for or on behalf of a person who lacks capacity must be done, or made, in his best interests". ${ }^{2}$ Section four specifically of the MCA provides best interests guidance and a framework, which must be followed when making a decision on another person's behalf. As mentioned previously, an LPA or Deputy of the Court has a legal right to make choices should the individual lack capacity at the time a decision needs to be made. However, if no LPA exists, a health care professional can be the recognized decision maker should a decision be required for a healthrelated issue. When making a "best interests" decision, the MCA states that consideration must be given to whether the person will regain capacity to make a decision and to encourage the person as far as practically possible to take part and participate in the decision making process. If an ADRT exists, the MCA insists that there should not be a desire to bring about death should the decision be related to life-sustaining treatment. The individual's past and present wishes, their feelings, values, and beliefs must also be taken into account when making a decision. The MCA also states that anyone who has an interest in the person's care, for example, a family and a friend, must also be included in the best interest process. ${ }^{2,34}$ Prior to the introduction of the best interests guidance within the MCA, clinical decisions made on behalf of another person were driven predominantly by the clinical agenda. However, these days the MCA promotes a holistic appraisal of need and decisions are not made solely based on health outcomes. Yet, worryingly, a report published 6 years after the introduction of the MCA, which explored the premature deaths of those with an intellectual disability, found that decisions were often made by one person, rather than the multidisciplinary group approach, which is advocated in the MCA. ${ }^{35}$ Furthermore, Heslop et $\mathrm{l}^{10}$ and Taylor ${ }^{11}$ found that health care professionals' decisions were influenced by prejudice and personal views and based on what they felt was the appropriate decision to be made. This was combined with a lack of information about the patient and family, which is required in order to achieve a truly holistic review. Noncom- pliance with the best interests checklist resulted in clinical decision making being manipulated to meet financial and bed pressures within a hospital. ${ }^{10}$ Therefore, this suggests that the findings of the studies cited overwhelmingly contradict the empowering ethos of the MCA.

However, the case of "Wye Valley NHS v Mr B" challenged the findings of these studies where a judge ruled in favor of respecting an individual's past and present wishes rather than placing a higher importance on the clinical need of the patient. ${ }^{36}$ In this instance, a 73-year-old gentleman who had a history of mental health problems developed a diabetic foot ulcer, which resulted in a deep bone infection. Clinically, Mr B required an above knee amputation to prevent sepsis and probable death yet he would not consent to this procedure and health care professionals believed that $\mathrm{Mr} \mathrm{B}$ lacked capacity to make the decision. Due to the associated risk, the case was referred to the Court of Protection, a high court dealing with issues specifically related to the MCA. The judge ruled that Mr B did lack the mental capacity into the decision regarding amputation; however, his expressed wishes and beliefs were given priority over clinical need and it was concluded to enforce surgery on this gentleman would not be in his best interests. ${ }^{36}$ This ruling is a prime example of a case demonstrating that the MCA has the ability to protect a person's right to have their wishes put to the forefront of the assessment, and clinical need is not always considered to be greater, even where death is a possible consequence of such a decision.

As identified in the best interests' framework, the individual's family or friends should be included in the process; however, there may be occasions when there is no one to consult. In this situation, a referral to an Independent Mental Capacity Advocate (IMCA) may be appropriate to enable an independent person to advocate on the patients behalf. The MCA specifies certain decisions when an IMCA must be involved; these include proposed serious medical treatment by an NHS body and/or changes in accommodation. ${ }^{2}$ This mandatory referral process has been challenged by the House of Lords ${ }^{1}$ as being too insular, and they suggest that the role of an IMCA should encompass a larger range of decisions. This will have a cost implication; however, it is hoped that costs would be recouped by the reduction in lengthy legal disputes and litigation costs. The role of the IMCA in the best interests' process is not to make the final decision but to submit a statement of findings to the responsible person in order for all the facts to be taken into account when reaching a decision. However, if the IMCA believes that the decision made was not in the best interests of the individual, they 
have a platform to raise challenge to this. Unfortunately, this process has resulted in complaints, undermining the role of the IMCA and the purpose to objectively advocate on another person's behalf. ${ }^{1}$ It is suggested that referral to an IMCA would benefit patient advocacy; however, there is inconsistency with referral rates to the IMCA service across the UK. This may be due to a lack of knowledge of the IMCA role among health care practitioners and the public. ${ }^{1}$ Referral rates may increase if there is greater scope of referral sources other than the local authority or NHS.

\section{Implication for nursing practice}

This literature review has produced a worthwhile discussion regarding the MCA and its implication to nursing practice and the practices of others within the wider health economy. The evidence suggests the MCA and its guiding principles are not yet sufficiently embedded into the practice of nurses and health care professionals. Therefore, it raises the question, how can a shift in culture can be achieved to ensure that the MCA is increasingly and sufficiently utilized within health care practice to guarantee that health care professionals are legally compliant and provide an assurance that the needs of those who require support to make decisions are provided. It is therefore suggested that an increase in training alongside a greater emphasis on the importance of the MCA would be a positive factor.

It is recognized that health care professionals have a responsibility and accountability to ensure that their knowledge is up to date and if there are any identified gaps they have a professional duty to address this. ${ }^{8,37}$ A further suggestion is for a greater integration of the MCA into undergraduate and postgraduate teaching programs for nurses and health care professionals as it has been established that an increase in training in a particular subject can increase knowledge in that particular area. ${ }^{38-41}$

This work has focused on the MCA and its implementation within England and Wales. However, it is suggested that these findings are transferrable on a wider global scale where the assessment of mental capacity takes place. As has been seen in this piece of work, example studies from America and Australia have echoed some of the findings of UK-based studies, ${ }^{13-17,24}$ confirming that assessing a person's mental ability to make a decision about their care can sometimes be a complex task.

Mental capacity legislation was introduced around the world when there were concerns that human rights should be considered an important aspect of making decisions about health care and treatment, and this was welcomed as a positive step forward in advocating for the rights of those who cannot participate in decision making. However, this method has not been adopted by every country. For example, in India, the western approach to mental capacity assessment is not supported. ${ }^{42}$

\section{Conclusion}

At its launch, the MCA was described as a visionary piece of legislation, which had the potential to empower and change the lives of many. Yet, 10 years on from implementation, the literature concurs that this vision is not embedded into practice as was initially intended. The findings of this detailed UK-based report are arguably generalizable to the wider global population due to the burden of those living with a diagnosed impairment of the mind or brain. Dementia alone has been declared a public health priority by the World Health Organization $^{37}$ as it is estimated that there are currently 50 million people worldwide living with this illness and this is set to triple by 2050 . Therefore, the assessment of mental capacity and advocating for those with a diagnosed cognitive impairment are not the problems confined solely to the UK.

The MCA brought a robust framework and an element of progression. As a result, the MCA gave people with mental impairment a voice. However, prior to the MCA implementation, decisions were often subjective, risk averse, and paternalistic. A postscrutiny report completed by the House of Lords was the catalyst to support improved application of the MCA in organizations and is now a priority for the UK Governments' health agenda. It is believed that by increasing knowledge and a greater awareness of the MCA, creating a source of central ownership for greater accountability, promoting the use of advance planning, and ensuring the MCA are viewed as fundamental, integral elements of care, rather than an optional extra; the principles and ethos of the MCA will be fully embedded into health care provision for patients. Nevertheless, a shift in culture is required in order for health care professionals to view the MCA as a tool that empowers and protects practitioners alongside patients rather than an unnecessary addition to an already busy and demanding health care environment.

\section{Disclosure}

The authors report no conflicts of interest in this work.

\section{References}

1. House of Lords. Mental Capacity Act 2005: Post-Legislative Scrutiny. London: House of Lords; 2014.

2. Department of Health. Mental Capacity Act 2005. London: The Stationery Office; 2005. 
3. Kalra A, Forman DE, Goodlin SJ. Medical decision making for older adults: an international perspective comparing the United States and India. J Geriatr Cardiol. 2015;12(4):329-334.

4. Snow HA, Fleming BR. Consent, capacity and the right to say no. Med J Aust. 2014;201(8):486-488.

5. Hatton C, Glover G, Emerson E, Brown I. People With Learning Disabilities in England 2015: Main Report. London: Public Health England; 2016.

6. Alzheimer's Research UK [homepage on the Internet]. Numbers of people in the UK; 2014. Available from: https://www.dementiastatistics. org/statistics/numbers-of-people-in-the-uk/. Accessed January 10, 2018.

7. Headway. Acquired brain injury 2013-2014 statistics based on UK admissions. Available from: https://www.headway.org.uk/media/2882/ brain-injury-statistics-2015-infographic.pdf.

8. Department of Health. Valuing Every Voice, Respecting Every Right: Making the Case for the Mental Capacity Act. London: The Stationery Office; 2014

9. Marshall H, Sprung S. The Mental Capacity Act: a review of the current literature. Br J Community Nurs. 2016;21(8):406-410.

10. Heslop P, Blair P, Fleming P, Hoghton M, Marriott A, Russ L. Poor adherence to the mental capacity act and premature death. The Journal of Adult Protection. 2014;16(6):367-376.

11. Taylor HJ. What are "best interests"? a critical evaluation of 'best interests' decision-making in clinical practice. Med Law Rev. 2016;24(2):176-205.

12. Kontos N, Freudenreich O, Querques J. Beyond capacity: identifying ethical dilemmas underlying capacity evaluation requests. Psychosomatics. 2013;54(2):103-110.

13. Williams V, Boyle G, Jepson M, Swift P, Williamson T, Heslop P. Best interests decisions: professional practices in health and social care. Health Soc Care Community. 2014;22(1):78-86.

14. Banner NF, Szmukler G. "Radical Interpretation" and the Assessment of Decision-Making Capacity. J Appl Philos. 2013;30(4):379-394.

15. Lennard C. Fluctuating capacity and impulsiveness in acquired brain injury: the dilemma of "unwise" decisions under the Mental Capacity Act. The Journal of Adult Protection . 2016;18(4):229-239.

16. Emmett C, Poole M, Bond J, Hughes JC. Homeward bound or bound for a home? Assessing the capacity of dementia patients to make decisions about hospital discharge: comparing practice with legal standards. Int J Law Psychiatry. 2013;36(1):73-82.

17. Owen GS, Freyenhagen F, Martin W, David AS. Clinical assessment of decision-making capacity in acquired brain injury with personality change. Neuropsychol Rehabil. 2017;27(1):133-148.

18. Mckinnon J. Pursuing concordance: moving away from paternalism. Br J Nurs. 2014;23(12):677-684.

19. Johnston C, Banner N, Fenwick A. Patient narrative: an "on-switch" for evaluating best interests. Journal of Social Welfare and Family Law. 2016;38(3):249-262.

20. Manthorpe J, Samsi K. Care professionals' understanding of the new criminal offences created by the Mental Capacity Act 2005. Int J Geriatr Psychiatry. 2015;30(4):384-392.

21. Marshall H, Sprung S. Community nurse's knowledge, confidence and experience of the Mental Capacity Act in practice. $\mathrm{Br} J$ Community Nurs. 2016;21(12):615-622.

22. Manthorpe J, Samsi K, Rapaport J. "More of a leg to stand on": views and usage of the Mental Capacity Act 2005 among staff of local Alzheimer's Society and carer organisations. Aging Ment Health. 2012;16(1):102-109.
23. Phair L, Manthorpe J. The use of the Mental Capacity Act among hospital patients: findings from a case study of one Acute Hospital Trust in England. The Journal of Adult Protection. 2012;14(6):259-270.

24. Rowley C, Perry D, Brickwood R, Mellor N. A Mental Capacity Act 2005 Questionnaire. Clin Ethics. 2013;8(1):15-18.

25. Manthorpe J, Samsi K. Changing practice: adapting to the Mental Capacity Act 2005. Social Care and Neurodisability. 2013;4(3/4): 124-133.

26. Willner P, Bridle J, Price V, Dymond S, Lewis G. What do NHS staff learn from training on the Mental Capacity Act (2005)? Legal Criminol Psychol. 2013;18(1):83-101.

27. Gough M, Kerlin L. Limits of Mental Capacity Act training for residential care homes. The Journal of Adult Protection. 2012;14(6):271-279.

28. Cummings S. Advanced decisions to refuse treatment in emergency situations. Emerg Nurse. 2014;22(8):16-18.

29. Mental Health Law Online [homepage on the Internet]. Kings College Hospital NHS Foundation Trust v C [2015] EWCOP 80 [2015] MHLO 125; 2015. Available from: http://www.mentalhealthlaw.co.uk/ King\%27s_College_Hospital_NHS_Foundation_Trust_v_C_(2015)_ EWCOP_80,_(2015)_MHLO_125.

30. Bartlett P, Mudigonda M, Chopra A, Morriss R, Jones S. Planning for incapacity by people with bipolar disorder under the Mental Capacity Act 2005. Journal of Social Welfare and Family Law. 2016;38(3):263-286.

31. Courts and Tribunals Judiciary [homepage on the Internet]. A local Authority and E (by her Litigation Friend the Official Solicitor) v A Health Authority and E's Parents. EWHC 1639 (COP) Case No: 12153212. Available from: https://www.judiciary.gov.uk/ judgments/a-local-authority-e-health-authority-15062012/.

32. Curtice M, Katuwawela I, Mccollum R. Lasting powers of attorney: implications for clinicians. Advances in Psychiatric Treatment. 2012;18(3):205-212.

33. Dening KH, Jones L, Sampson EL. Preferences for end-of-life care: a nominal group study of people with dementia and their family carers Palliat Med. 2013;27(5):409-417.

34. Griffith R, Tengnah C. Mental Capacity Act: determining best interests. Br J Community Nurs. 2008;13(7):335-341.

35. Brown H, Marchant L. Using the Mental Capacity Act in complex cases. Tizard Learning Disability Review. 2013;18(2):60-69.

36. Series L. The Place of Wishes and Feelings in best interest decisions. Wye Valley NHS Trust v Mr B. Mod. L. Rev. 2016;79(6):1101-1115.

37. World Health Organization [homepage on the Internet] Dementia, A public health priority; 2017. Available from: http://www.who.int/ mental_health/neurology/dementia/infographic_dementia/en/.

38. Nursing and Midwifery Council. The Code: Professional Standards of Practice and Behaviour for Nurses and Midwives. London: Nursing and Midwifery Council; 2015.

39. Abe Y, Kawahara C, Yamashina A, Tsuboi R. Repeated scenario simulation to improve competency in critical care: a new approach for nursing education. Am J Crit Care. 2013;22(1):33-40.

40. Mcgarry J, Baker C, Wilson C, Felton A, Banerjee A. Preparation for safeguarding in UK pre-registration graduate nurse education. The Journal of Adult Protection. 2015;17(6):371-379.

41. Mackie JE, Bruce CD. Increasing nursing students' understanding and accuracy with medical dose calculations: A collaborative approach. Nurse Educ Today. 2016;40:146-153.

42. Tiwari S, Pandey N. Need for Mental Capacity Act and its assessment in India. Journal of Geriatric Mental Health. 2014;1(2):79-81. 


\section{Publish your work in this journal}

Nursing: Research and Reviews is an international, peer-reviewed, open access journal publishing original research, reports, reviews and commentaries on all aspects of nursing and patient care. These include patient education and counseling, ethics, management and organizational issues, diagnostics and prescribing, health outcomes, economics and manuscript management system is completely online and includes a very quick and fair peer-review system. Visit http://www.dovepress. com/testimonials.php to read real quotes from published authors.

Submit your manuscript here: https://www.dovepress.com/nursing-research-and-reviews-journa 